
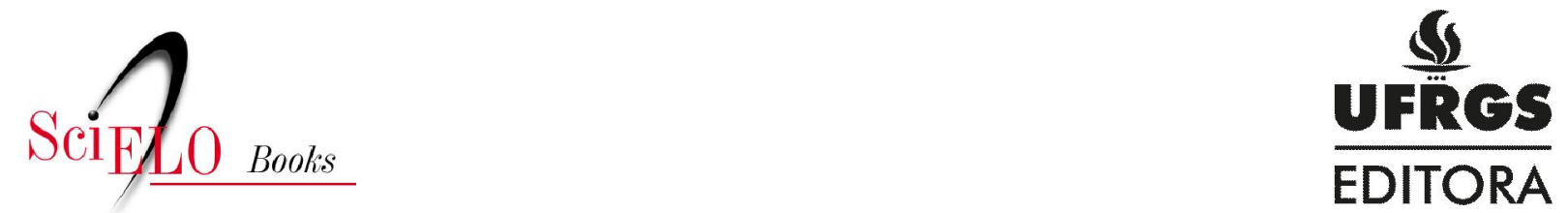

\title{
7 - Viajantes brancos na África negra do século XV
}

\author{
Eder da Silveira \\ Silvio Marcus de Souza Correa
}

SciELO Books / SciELO Livros / SciELO Libros

SILVEIRA, E., and CORREA, SMS. Viajantes brancos na África negra do século XV. In: MACEDO, JR., org. Desvendando a história da África [online]. Porto Alegre: Editora da UFRGS, 2008.

Diversidades series, pp. 85-96. ISBN 978-85-386-0383-2. Available from: doi:

10.7476/9788538603832. Also available in ePUB from:

http://books.scielo.org/id/yf4cf/epub/macedo-9788538603832.epub.

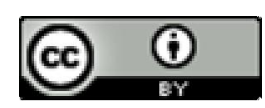

All the contents of this work, except where otherwise noted, is licensed under a Creative Commons Attribution 4.0 International license.

Todo o conteúdo deste trabalho, exceto quando houver ressalva, é publicado sob a licença Creative Commons Atribição $\underline{4.0}$.

Todo el contenido de esta obra, excepto donde se indique lo contrario, está bajo licencia de la licencia Creative Commons $\underline{\text { Reconocimento } 4.0 .}$. 


\title{
7 \\ VIAJANTES BRANCOS \\ NA ÁFRICA NEGRA DO SÉCULO XV
}

\author{
Eder da Silveira \\ Silvio Marcus de Souza Correa
}

A tomada de Ceuta em 1415 e o início das viagens atlânticas sob o patrocínio da Coroa portuguesa não são frutos de mero acaso e nem mesmo explicáveis por questões prosaicas, como a proximidade do norte africano e suas ilhas atlânticas com relação a Portugal. Cabe lembrar que, na antigüidade, a Lusitânia e o norte africano estiveram sob domínio do Império Romano. Durante a Idade Média européia, a relação entre ibéricos e magrebinos assumiu novos contornos com a presença moura na Península Ibérica. O prolongado convívio dos peninsulares cristãos com os mouros favoreceu, além das trocas mercantis, um conhecimento indireto sobre o interior da África, sobre suas gentes e, principalmente, sobre uma terra aurífera para além do deserto. Com base no estudo de Jean Devisse (1972), pode-se supor que o comércio entre a África Ocidental e o Mediterrâneo durante a Baixa Idade Média favoreceu a acumulação de um conhecimento empírico por parte dos europeus sobre a hinterlândia africana e, principalmente, sobre o ouro sudanês.

Às vésperas da expansão portuguesa pela costa ocidental da África, a Coroa lusa estava, pois, ciente da importância da posição estratégica de Ceuta, onde um entreposto seria promissor. Como sublinhou Charles Boxer (2002, p. 35), aquele era "um dos portos terminais do comércio transaariano do ouro". A sua conquista significava a abertura do caminho ao tão desejado ouro sudanês. Porém, a presença portuguesa no norte marroquino bastou para Ceuta deixar de ser um ponto de destino das cáfilas (Costa e Silva, 2002, p. 151). 
Com os pés na África, os portugueses começaram a molhá-los no Atlântico e a secá-los nas ilhas Canárias e dos Açores. Logo, já estavam em terra firme, passando o Cabo Bojador e alcançaram a Guiné antes de chegar à metade do século XV. Desde então, o ouro africano passou a chegar a Lisboa devido ao trato direto na costa da Guiné (Braudel, 1990, p. 144). Apesar da presença portuguesa cada vez mais regular na costa africana durante a segunda metade do século XV, o metal amarelo continuou chegando ao Mediterrâneo através das rotas do Saara. Alberto da Costa e Silva (2002, p. 215) concorda que o comércio atlântico provocou mudanças na economia africana e também nas relações política e militar entre grupos praieiros e aqueles do interior da Guiné, porém as caravanas não perderam a sua importância mercantil para os africanos com a chegada das caravelas. Mas as relações luso-africanas não se reduzem ao comércio. Além do interesse pelo ouro e por outras riquezas, demais interesses foram apontados pelos cronistas dos séculos XV e XVI, como Rui de Pina, Gomes Eanes de Zurara, Duarte Pacheco Pereira e João de Barros. Estes mencionam os diversos motivos dos portugueses em seu périplo africano. Assim, a formação de um império, as alianças com grupos africanos e a tentativa de cristianização de populações costeiras foram práticas dos portugueses e de outros europeus a serviço ou com a licença do Infante D. Henrique, durante as primeiras expedições lusas à África.

Em sua Crônica do Descobrimento e da Conquista da Guiné, o cronista Gomes Eanes de Zurara afirmou que as primeiras viagens portuguesas de reconhecimento da costa ocidental africana tiveram como objetivos a) explorar as terras ao sul das Ilhas Canárias; b) estabelecer laços de comércio com seus habitantes; c) informar-se sobre a expansão e a influência muçulmana no interior do continente; d) procurar populações cristãs prontas para auxiliar na luta contra os infiéis; e) expandir o cristianismo. O historiador Charles Boxer (2002, p. 34) chamou a atenção para a constelação de fatores da expansão, composta (a) pelo espírito de cruzada; (b) pela sanha do 
ouro; (c) pela busca de um reino mítico do Preste João; e (d) pela procura de especiarias.

Há, no entanto, uma corrente historiográfica que privilegia os fatores econômicos da expansão marítima. A abordagem macrohistórica do tema prima, em geral, pela formação econômica do mercantilismo na Europa, para a qual a expansão ultramarina e o tráfico negreiro seriam desdobramentos necessários ao desenvolvimento do capitalismo comercial. Essa abordagem macrohistórica perde de vista as motivações e as impressões mais "miúdas".

Para o estudo da História, os modelos teóricos, seus conceitos e seu esquema interpretativo são, muitas vezes, de difícil compreensão para o público leigo ou mesmo para os estudantes de História. Não raro, as interpretações macrohistóricas incorrem em esquemas artificiais que acabam por tolher qualquer compreensão de realidades pretéritas.

Sem abandonar um referencial teórico e um rigor metodológico que prescindem à interpretação e à própria escrita da História, acreditamos que a análise dos relatos de viagem pode auxiliar a conectar interesses e motivações individuais e aquilo que era parte de um projeto maior de grupos mercantis e das realezas européias. A literatura de viagem oferece à pesquisa histórica uma valiosa fonte documental. Destaca-se nessa literatura a descrição das viagens à África negra (1455-1456), do veneziano Alvise Cadamosto, e da viagem à costa da Guiné e à Península Ibérica (1479-1481), do flamengo Eustache Delafosse. Ambos os relatos se inscrevem numa narrativa moderna sobre a costa ocidental africana e suas gentes.

Se, de modo geral, as crônicas reais de Gomes Eanes Zurara, Rui de Pina, João de Barros e outros dão maior atenção aos feitos da lusitanidade, os relatos de Cadamosto e Delafosse nos oferecem elementos mais "miúdos” das navegações. Esses relatos não revestem as ações dos europeus na África de uma missão evangélica ou salvacionista. Nos relatos do veneziano e do flamengo, os portugueses não aparecem como um povo predestinado, como os cro- 
nistas portugueses e mesmo alguns poetas e historiadores modernos declararam ou insinuaram. Como exemplo, poderíamos lembrar alguns versos de Fernando Pessoa (1996, p. 55), para quem as ações individuais representavam uma vontade coletiva, ao mesmo tempo popular e monárquica:

Aqui ao leme sou mais do que eu: Sou um povo que quere o mar que é teu; $\mathrm{E}$ mais que o mostrengo, que me a alma teme E roda nas trevas do fim mundo, Manda a vontade, que me ata ao leme, De El-Rei D. João Segundo!

O poeta ainda considerou válido todo o esforço humano para um povo predestinado; afinal, para cruzar o mar, "quantas mães choraram, quantos filhos em vão rezaram! Quantas noivas ficaram por casar para que fosses nosso, ó mar!’”. O ufanismo na literatura e em toda uma historiografia portuguesa tradicional minimiza ou mesmo anula as motivações individuais, as ações e as interações humanas cujos efeitos inusitados demonstram o quanto qualquer processo histórico deve à contingência.

Os relatos de Cadamosto e Delafosse se afastam de qualquer mística ou predestinação e realçam de forma particular as dimensões mais ordinárias e mais subjetivas da aventura de lançar-se ao mar. Além disso, os relatos de viagens nos oferecem certas conexões entre outras histórias que escapam aos esquemas macroestruturais de quase toda "história geral" ou teleológica. Escusado lembrar que muitos relatos de viajantes serviram como fonte para cronistas e historiadores. Além disso, alguns deles foram como etnógrafos avant la lettre na interpretação e na representação da alteridade e da diversidade cultural na África negra.

\section{O Conhecimento sobre a África Negra na Europa Ocidental}

Durante a Idade Média, as referências literárias ao negro baseavam-se quase exclusivamente na tradição bíblica e em alguns 
textos da Antigüidade greco-romana. José Rivair Macedo (2001) apresentou uma síntese do saber enciclopédico medieval na Península Ibérica sobre os africanos como "filhos de Cam". Porém, a iconografia ibérica e flamenga dos séculos XV e XVI aponta para um conhecimento mais "realista" que advém do comércio atlântico. No acervo do Museu do Prado, em Madri, vários quadros representam figuras negras. Entre elas, destacam-se as pinturas Adoração dos reis magos, de Hans Memling (c.1453-1494) e de Jerônimo Bosch (c.1450-1516). Deste último, ainda há o famoso tríptico O jardim das delícias, em cujo painel central há várias figuras negras. No painel da esquerda, animais africanos, como elefante, girafa e porco-espinho, estão representados.

Sobre os africanos que serviram de modelo aos pintores, gravuristas e desenhistas europeus da Renascença, pouco se sabe. De Albert Dürer há um desenho que retrata um negro (1508) e outro uma negra "moura” de nome Catarina (1521). Esta última era doméstica do português João Brandão (Eichler, 1999, p. 114).

Além das informações que eram obtidas dos africanos levados para a Europa, o comércio mediterrânico com o norte da África permitiu que os europeus obtivessem informações indiretas sobre as populações do interior da África.

Desde a tomada de Ceuta em 1415 até o final do périplo africano em 1498, os portugueses acumularam várias experiências (mercantil, militar, diplomática, cultural) na África. Após a passagem do Cabo Bojador em 1434, os portugueses alcançaram a Guiné e o Cabo Verde uma década depois. Chegaram à Costa da Malagueta em 1470. Dali, eles fincaram pé em área vizinha, onde construíram a fortaleza d'El Mina em 1482. Na mesma década, Diogo Cão explorou a embocadura do Rio Zaire, e Bartolomeu Dias alcançou a estremadura austral da África. Em 1497, Vasco da Gama ainda fincou padrões na costa africana antes de chegar à Índia e tratou com africanos da costa índica, embora nem sempre de maneira amistosa. 


\section{A Presença Portuguesa na Costa Africana no Século XV}

Dessa experiência luso-africana do século XV, há uma copiosa documentação. Dela se destaca a Monumenta Henricina, coleção organizada por Dias Dinis (1960) e obra imprescindível para os estudos dos primórdios das relações luso-africanas. Coleção mais recente é Portugalie Monumenta Africana, a qual reúne, em dois volumes, 480 documentos relativos às atividades portuguesas na África desde 1443 até 1499. A natureza desse material é variada: bulas papais, tratados, cartas de mercês, cartas de doação ou de privilégios, cartas de procuração, registros notariais e alvarás.

Escrita em 1448, a Crônica do Descobrimento e da Conquista da Guiné, de Gomes Eanes de Zurara, contém importantes informações sobre os primeiros contatos dos europeus com os habitantes das Canárias, com os mouros do Saara e com os negros da chamada Guiné. Deprima inventione Guinee, do português Diogo Gomes, também faz parte deste inventário documental, com informações valiosas sobre os reinos mandingas. Outro documento importante para o século XV é o já mencionado relato das viagens (1455-56) do veneziano Alvise Cadamosto, publicado pela primeira vez em 1507. Outras fontes alusivas à Guiné são os livros Esmeraldo de Situ Orbis, de Duarte Pacheco Pereira; Descrição da costa ocidental da Africa, de Valentim Fernandes, e Décadas, de João de Barros. Outras referências dignas de nota sobre a Guiné são: os relatos das navegações do português Pedro de Sintra (1460) e do comerciante flamengo Eustache Delafosse (1479-1481). Já a Relação do Reino do Congo, de Rui de Pina, se constitui fonte importante para os estudos das relações luso-africanas no Congo no último quartel do século XV.

\section{Viajantes Brancos na África Negra}

Apesar da copiosa documentação portuguesa sobre a África atlântica, o relato de Cadamosto tem uma particularidade inigualável. 
No que concerne à alteridade africana, esta foi percebida de forma original pelo veneziano. Sua visão é fundamentalmente moderna. Ela difere da imagem medieval e tampouco se orienta pela tradição bíblica ou pelos clássicos antigos como Heródoto, Ptolomeu e Plínio. As fantasias e as imagens mitológicas, presentes nas cartografias e nas descrições clássicas e medievais, já não aparecem no seu relato de viagem (Correa, 2002, p. 111).

Posto a serviço do Infante Dom Henrique, Cadamosto foi um dos vários italianos a se aventurar pelo Atlântico. As suas duas viagens (1455-1456) à África negra se integram à fase pioneira dos "descobrimentos portugueses". A partir de sua experiência africana, Cadamosto deu informações importantes sobre o potencial econômico da chamada Guiné, sobre a influência muçulmana na África negra e sobre as possibilidades de uma expansão do cristianismo naquela região. O relato de suas viagens revela também certos interesses pessoais do veneziano, bem como da Coroa portuguesa. Além disso, informa sobre certos grupos africanos, alguns interessados, outros não, em manter contato com os europeus.

No relato do veneziano sobre a Guiné, escravos já são mencionados. O próprio Cadamosto, inicialmente mais interessado em negociar seus cavalos por ouro, ao invés do metal amarelo, obteve como pagamento pelos animais africanos escravizados. Diogo Gomes, Valentim Fernandes e Duarte Pacheco Pereira também mencionam a escravidão africana e a certa facilidade dos portugueses em obter escravos. Mas na segunda metade do século XV, a demanda européia por escravos africanos é ainda pequena quando comparada à dimensão que ela adquire a partir da colonização do Novo Mundo.

Desde o início do contato com as gentes da Guiné, os europeus já enfrentavam hostilidades e certas dificuldades em mercadejar em algumas partes da costa. Em 1446, o português Nuno Tristão e sua tripulação foram atacados num dos rios da Senegâmbia, onde as flechas ervadas dos africanos causaram várias baixas entre os portugueses. Quase dez anos depois, o genovês Usodinare e o veneziano Ca- 
damosto tiveram dificuldades em mercadejar por aquela costa. Já o português Diogo Gomes conseguiu adentrar aquela região e tratar com os mandingas. Depois dele, os portugueses passaram a freqüentar anualmente o Rio Gâmbia, o Casamansa, o São Domingos (ou Cacheu) e o Rio Grande (Niane, 1989, p. 31).

Vários historiadores (Niane, 1989, p. 28; Braudel, 1990, p. 137; Costa e Silva, 2002, p. 204) atentaram para a concomitância da presença cada vez mais regular dos portugueses na costa da Guiné com o declínio do Império do Mali e a ascensão do Império Songai. Mas isso não significa uma correlação direta entre o dinamismo econômico nas províncias ocidentais dos mandingas a partir da segunda metade do século XV e a presença européia na costa atlântica.

Quando morre o Infante Dom Henrique (1460), os portugueses já mantêm uma presença constante na Guiné. Para manter o comércio ultramarino e as expedições marítimas em curso, a Coroa portuguesa buscou um consórcio com a empresa privada. Através de um contrato com o burguês lisboeta Fernão Gomes (1468-1474), o rei D. Afonso V lhe concedeu o monopólio comercial da Guiné.

Tal monopólio não foi respeitado pelos castelhanos que visavam fazer trato e resgate na Guiné. Duarte Pacheco Pereira nos informa sobre o naufrágio na Costa da Malagueta de um navio flamengo sob comando castelhano e sobre o infortúnio de seus tripulantes. O consórcio espanhol e flamengo não parou por aí, pois outro navio foi capturado pelos portugueses e sua tripulação levada para Lisboa para ser enforcada por crime de contrabando. Entre os prisioneiros, estava o comerciante flamengo Eustache Delafosse, cujo relato é rico em informações sobre o comércio na costa africana, inclusive de escravos. Cabe lembrar que, assim como Cadamosto, Delafosse comprou e vendeu escravos africanos.

Enquanto os portugueses, espanhóis e flamengos concorriam na costa da Guiné, relações conflituosas entre as coroas ibéricas ga- 
nhavam novos contornos no campo diplomático, no qual um tratado luso-castelhano foi firmado em setembro de 1479, sendo ratificado pelos reis católicos em março de 1480.

Após o êxito comercial de Fernão Gomes, do tratado luso-castelhano de Alcaçovas (1479) e da bula papal aterni regis (1481), em que o Papa Xisto IV ratificou as cláusulas da partilha das zonas de influência das coroas ibéricas, a Coroa portuguesa resolveu instalar um forte na costa africana. Diogo Azambuja escolheu o local em 1482 e negociou com líderes locais a aquiescência para tal fundação. O famoso forte São Jorge de Mina foi construído em poucas semanas e, a partir de então, os portugueses tentaram obter maiores vantagens comerciais, além de consolidar suas alianças com grupos africanos e, na medida do possível, convertê-los ao cristianismo. Porém, a situação não era das mais favoráveis para a instalação permanente de portugueses naquelas bandas. Além de alguns mal-entendidos, os portugueses desconheciam muitas regras sociais, culturais e religiosas das comunidades locais. A presença permanente de portugueses logo teria um custo elevado, e poderíamos dizer que os portugueses não premeditaram alguns embaraços naquela costa, onde os reinos faziam muitas exigências para tolerar estrangeiros na periferia de suas áreas de influência.

A minuciosa pesquisa do historiador africano Ballong (1993) demonstra como os portugueses "se africanizaram" na Costa da Mina, onde as trocas comerciais, nas quais os portugueses eram às vezes meros intermediários, as alianças e o modus vivendi acusam a predominância cultural africana. No entanto, os portugueses também foram hábeis em suas alianças comerciais e político-militares com os reinos vizinhos, especialmente de Eguafo e Fetu.

Além da aliança com certos grupos da Costa da Mina, os portugueses ainda selaram alianças importantes com os ntotila do Congo a partir de 1482. A cristianização do manicongo teve desdobramentos importantes para as relações luso-congolesas e, assim como na Costa da Mina, os portugueses lograram fazer parte da complexa rede comercial da costa africana. Muitas mercadorias européias eram introduzidas 
no comércio africano por mãos portuguesas, mas muitas mercadorias africanas eram trocadas nos mercados africanos por essas mesmas mãos.

Em outras palavras, os portugueses serviram também de intermediários do comércio africano e acabaram por ampliá-lo em termos inter-regionais pela via marítima. No último quartel do século $\mathrm{XV}$, os portugueses navegavam por toda a costa atlântica da África. Em muitas regiões costeiras, o comércio com os portugueses alterou a organização social e econômica e também as relações políticas, militares e comerciais entre reinos praieiros e destes com aqueles do interior.

Valetim Fernandes (1951, p. 61-64), por exemplo, foi um dos que mencionou a influência portuguesa na rede comercial dos mandingas. Os portugueses chegaram a fundar uma vila no interior da Gâmbia, onde eles prometeram ajudar militarmente seus aliados mandingas. A propósito, João de Barros nos informa que o caramansa chegou a pedir ajuda militar a D. João II diante da ofensiva fula em 1490. O rei português enviou uma embaixada ao seu aliado, mas nada de auxílio militar. Em 1535, houve mais um apelo mandinga aos portugueses e, novamente, a ajuda militar não veio. Outros aliados africanos também ficaram sem receber o apoio prometido ou suas demandas não foram atendidas pelos portugueses. As cartas do manicongo D. Afonso, expedidas entre 1512 e 1540, acusam o impasse, a omissão, o paradoxo e a dubiedade da Coroa portuguesa com seus aliados congos.

\section{Considerações Finais}

O poeta e historiador Alberto da Costa e Silva escreveu com toda propriedade e no melhor estilo sobre as possíveis impressões de estranhamento que os africanos da costa tiveram ao ver chegar os forasteiros, de pequena estatura, com seus cabelos lisos e longos, suas faces rosadas e barbudas, o nariz comprido, os lábios estreitos e uma pele muito desbotada. Aquela gente branca parecia não ter artelhos e cheirava muito mal. Alguns deles, vítimas do escorbuto, tinham uma 
boca desdentada e sangrenta. Não raro, eram os que tinham uma pele sarnenta, que desciam à praia num péssimo aspecto, adoentados, com febres ou infestados de pulgas e piolhos.

Essa gente era, contudo, obstinada e muito curiosa. Fazia muitas perguntas sobre a região, suas riquezas, seus régulos, suas gentes, sua religião. Apesar de mostrarem grande fragilidade física às doenças tropicais, aqueles homens tinham armas mortíferas que cuspiam fogo e faziam grande estrondo como trovão. Traziam muitas mercadorias que interessavam os africanos, outras nem tanto. Tinham enormes embarcações e singravam os mares com rapidez, alcançando terras e ilhas inatingíveis à navegação de cabotagem dos africanos.

Durante todo o século XV, esses forasteiros foram se fazendo cada vez mais presentes na costa africana do Atlântico, selaram alianças com alguns africanos e entraram em contendas com outros. Tiveram filhos mestiços, enriqueceram alguns comerciantes, régulos e reis e empobreceram outros, incrementaram o comércio local com novas mercadorias, mas tiraram da terra muitos de seus filhos através da compra e venda de escravos. Profanaram locais sagrados, queimaram ídolos e trouxeram uma nova religião. Interferiram também na paisagem litorânea da África, onde introduziram animais e vegetais vindos da Europa ou da Ásia, estabeleceram padrões, ergueram cruzes, construíram capelas, feitorias e fortalezas.

Ao final do século XV, as relações luso-africanas haviam se intensificado na costa atlântica. Essa experiência africana marcaria indelevelmente as relações luso-indianas e luso-brasileiras das primeiras décadas dos Quinhentos. Aliás, não é de se estranhar que, na segunda viagem para a Índia, o capitão-mor Pedro Álvares Cabral mandou descer um batel à praia de uma terra recém-avistada, onde o primeiro contato se deu como na África. Afinal, um negro grumete se dirigiu em língua da Guiné àquela gente "de cor baça e de cabelo comprido e corredio, e a figura do rosto coisa mui nova" (Barros, 1982, p. 107-108). Se levarmos em conta o triste fim do turgimão negro da tripulação do genovês Antoniotto Usodinare ao descer num rio da 
Senegâmbia em 1455, podemos supor que o grumete sabia o risco que corria ao abrir a boca em outras praias. Diante da incompreensão daquela língua africana, tentaram alguns marinheiros ainda se comunicar em árabe. Sem saber nenhuma língua africana e tampouco o árabe, aquela gente praieira pareceu, aos portugueses, mais próxima àquela encontrada pelos castelhanos em suas viagens ao Poente. Deduziram que haviam chegado a outra margem do Atlântico, após quase um século de experiência na costa africana.

\section{Referências}

BALLONG, J. Bato’ora. São Jorge da Mina. 1482-1637. Lisboa: Fundação Calouste Gulbenkian, 1993.

BARROS, João de. Décadas (Selecção, Prefácio e Notas de António Baião). Lisboa: Livraria e Editora Sá da Costa, 1982.

BRAUDEL, Fernand. La Méditerranée et le monde méditerranéen à l'époque de Philippe II., 9 $9^{\text {ème }}$ edition. Paris, 1990.

CADAMOSTO, Alvise. Voyages en Afrique Noire (tradução e notas de Frédérique Verrier). Paris: Editions Chandeigne/Unesco, 1994. 